All guests were received by one of the Vice-Presidents of the Supreme Soviet.

Miss Tombet visited the Tracing Bureau of the Alliance, which works in close touch with the ICRC Central Tracing Agency.

\title{
RED CROSS AND NURSING
}

Towards the end of last year, Miss Yvonne Hentsch, Under Secretary General of the League of Red Cross Societies, in charge of the Services to National Societies Sector and former director of the Nursing Bureau, retired. She had served on the League Secretariat since 1939 and her broad knowledge of nursing problems and her exemplary competence in social work had earned her the esteem of various circles in both the nursing and the Red Cross worlds. As Miss M. Duvillard, a member of the ICRC wrote, "Yvonne Hentsch, it seems, has the secret of the really universal Red Cross language which dispenses with words and goes straight to the heart".

Miss Hentsch recently published, under the title Red Cross and Nursing, ${ }^{1}$ a study from which we are pleased to quote, because it is of vital interest and examines problems which are very topical. We hope that she will see our doing so as a tribute. (Ed.)

\section{...Adapting to change}

The rapid evolution which is characteristic of today's world has affected, needless to say, both the Red Cross and nursing. The demands made on them are changing because the needs of society are different. In the field of nursing education, National Societies can afford less and less the expense of running schools of nursing offering a basic programme unless the Government entrusts them with this task and provides the necessary funds. More and more also, advanced studies in nursing are part of univer-

1 See Panorama (1973, No. 1), League of Red Cross Societies, Geneva. 
sity programmes and therefore there is less need for the Red Cross to undertake them. Instead, some National Societies are offering scholarships for such studies to nurses who upon returning to their country assume leadership positions. The League strongly supports such action and assists the donor Societies in the selection of suitable candidates when the latter are nationals of another country than the one where the studies are to be undertaken.

To meet increasing nursing needs the existence in most countries of a well-qualified nurse assistant has become imperative. In some countries the National Society has undertaken this training. In the majority of cases, however, the latter is in the hands of other institutions while the Red Cross concentrates on preparing volunteer nursing auxiliaries and hospital aids.

With regard to health education, it has become such an integral part of nursing and of all public health programmes that there is less need for the Red Cross to pioneer in this field. On the other hand, however, the National Society is often requested to take over these activities until such time as they can be carried out by the official public health services.

One traditional obligation of National Societies is " in time of war and if the need arises to assist the Army Medical Services by every means in its power" (Geneva International Conference, 1863, Resolutions, Chapter 1, Article 1). In the early days of the Red Cross this often meant providing practically the whole nursing service required in time of conflict. Over the last 25 years the military authorities of most countries have established their own nursing services, thus leaving for National Societies in most cases only a complementary role to play in this respect.

Nevertheless the obligation remains for National Societies to furnish whatever personnel may be needed. In addition these Societies are increasingly required by the civilian authorities to intervene and even to assume leadership in disaster relief operations. Nursing personnel is often needed and must be prepared and readily available at all times to join in such operations, nationally or internationally. To help National Societies to meet this responsibility, the League has prepared a set of special guidelines. While geared to disaster nursing, these guidelines meet the requirements of the Principles and Rules for Red Cross Disaster Relief as approved 


\section{IN THE RED CROSS WORLD}

by the XXI International Conference of the Red Cross, Istanbul, 1969.

Changing demands have changed the aspect of the Red Cross nursing services rendered to the community as compared to what they were 100 years ago. Such services, however, in meeting new needs fulfil a vital role and they will continue to do so in the foreseeable future, provided both the National Societies and the nursing profession remain at the same time open to change and true to the fundamental principle of Humanity which they have in common.

\section{Tomorrow's challenge}

In the different countries of the world both old and new, National Societies are called upon to serve communities that are not only different from one another but the needs of which also fluctuate within the same communities. In most of them there is at all times need for some extra service that is not provided by the official authorities, however well equipped and organized. Hopefully, too, there is in all of them room for some kind of neighbourly volunteer service that makes the world of some people a better and happier place to live in. It is those kinds of services that are a challenge to Red Cross. They are also a challenge to nursing because, in the community, nurses are in a particularly good strategic position to detect human needs and more specifically health needs. As part of the health team they are also prepared to take their share of responsibility in meeting these needs.

Tomorrow's challenge for the Red Cross lies in its ability to attract the best of the nursing resources that are available to serve in times of conflict and disaster as well as in permanent health programmes. For nursing, the challenge is to recognise that the Red Cross provides a channel of service where nursing ideals and principles apply and where all nursing skills are needed.

To meet such a challenge leadership is required, nationally and internationally, on the part of both National Societies and of the nursing profession. If together they keep on seeking new ways of meeting changing community needs, then Red Cross and Nursing will continue to make an exciting and worthwhile story. 